\title{
AVIAN CORONAVIRUS INFECTION INDUCES MANNOSE- BINDING LECTIN PRODUCTION IN DENDRITIC CELL PRECURSORS OF CHICKEN LYMPHOID ORGANS
}

\author{
Attila FARSANG ${ }^{1 \dagger^{*}}$, Ildikó BÓDI ${ }^{2}$, Orsolya FÖLKER ${ }^{2}$, Krisztina MINKÓ $^{2}, Z^{2}$ sófia BENYEDA ${ }^{3}$, \\ Ádám BÁLINT ${ }^{4}$ and Imre OLÁH ${ }^{2}$ \\ ${ }^{1}$ National Food Chain Safety Office, Directorate of Veterinary Medicinal Products, \\ Budapest, Hungary; †Present address: Ceva-Phylaxia Co. Ltd., Szállás u. 5, \\ H-1107 Budapest, Hungary; ${ }^{2}$ Department of Anatomy, Histology and Embryology, \\ Faculty of Medicine, Semmelweis University, Budapest, Hungary; \\ ${ }^{3}$ Prophyl Ltd., Mohács, Hungary; ${ }^{4}$ National Food Chain Safety Office, \\ Veterinary Diagnostic Directorate, Budapest, Hungary
}

(Received 27 September 2018; accepted 20 February 2019)

The aim of this immunocytochemical study was to compare mannosebinding lectin (MBL) production induced by avian coronavirus in the spleen and caecal tonsil (CT). One-day-old specific-pathogen-free (SPF) chickens were experimentally infected with six QX field isolates and the H120 vaccine strain. In the negative control birds, the spleen was MBL negative, while the CT showed scattered MBL-positive cells in close proximity and within the surface epithelium and germinal centre (GC)-like cell clusters. MBL was detectable in the ellipsoidassociated cells (EACs) and cell clusters in the periarterial lymphoid sheath (PALS) by 7 days post infection (dpi). In both organs, the MBL-positive cells occupy antigen-exposed areas, indicating that GC formation depends on resident precursors of dendritic cells. The majority of MBL-positive EACs express the CD83 antigen, providing evidence that coronavirus infection facilitated the maturation of dendritic cell precursors. Surprisingly, co-localisation of MBL and CD83 was not detectable in the CT. In the spleen (associated with circulation), the EACs producing MBL and expressing CD83 are a common precursor of both follicular (FDC) and interdigitating dendritic cells (IDC). In the CT (gut-associated lymphoid tissue, GALT) the precursors of FDC and IDC are MBL-producing cells and CD83-positive cells, respectively. In the CT the two separate precursors of lymphoid dendritic cells provide some 'autonomy' for the GALT.

Key words: Avian coronavirus, mannose-binding lectin, precursor of follicular dendritic cell, spleen, caecal tonsil

Infectious bronchitis virus (IBV) is a coronavirus of domestic fowl (Gallus gallus domesticus). The name of the virus refers to its ability to induce upper

*Corresponding author; E-mail: attila.farsang@ceva.com; Phone: 0036 (1) 262-9505/ext. 4577 
respiratory disease; however, IBV can also replicate in other non-respiratory epithelial cells in the kidney (Cumming, 1962; Kinde et al., 1991; Picault et al., 1991; Lambrechts et al., 1993), the Harderian gland (Gelb et al., 1991; Toro et al., 1996), the liver (Ambali and Jones, 1990), and even in semen and eggs (Cook, 1971). The presence of IBV was reported in the bursa of Fabricius (Cavanagh, 2007) and in the spleen without causing functional damage (Otsuki et al., 1987, 1990; Dhinakar Raj and Jones, 1997). The innate immune system operates with both cellular elements including macrophages, natural killer (NK) cells, dendritic and mast cells, and soluble molecules like type II interferon, complement and collectins. The collectin family includes surfactant proteins (SP-A, SP-D, chicken lung lectin, cLl, without collagen domain) and mannose-binding lectin (MBL). MBL-A and MBL-C were described in mammals, but in chickens only one form of MBL can be found and the MBL gene locates on chromosome 6 (Laursen et al., 1998). MBL is mainly expressed in the liver of chickens. The serum level of MBL varies between 0.4-37.8 $\mu \mathrm{g} / \mathrm{ml}$ (Nielsen et al., 1999) and a relationship has been revealed between MBL serum level and the severity of disease in the case of IBV infection as well as in many other infections caused by Salmonella spp., Pasteurella multocida and Ascaridia galli (Nielsen et al., 1999; Schou et al., 2010; Kjaerup et al., 2013, 2014; Dalgaard et al., 2015; Ulrich-Lynge et al., 2015a,b; Zhang et al., 2017). MBL has multiple immune functions such as opsonisation, complement activation by initiating the lectin pathway, clearance of apoptotic cells, and regulation of inflammation and the adaptive immune response (Ulrich-Lynge et al., 2015b; Hamzić et al., 2016).

One of the major cellular players of innate and adaptive immunity is the dendritic cell. An infectious agent and/or an inflammatory stimulus have two significant effects on the dendritic cell precursors: stimulate maturation and induce the expression of surface markers like CD83, and facilitate migratory capability (Flores-Romo, 2001; Gunn, 2003; Randolph et al., 2005). CD83 is a soluble glycoprotein belonging to the immunoglobulin superfamily (Zhou et al., 1992; Hock et al., 2001; Lechmann et al., 2002; Prazma and Tedder, 2007) and the most significant maturation marker of dendritic cells (Zhou and Tedder, 1995; Prechtel and Steinkasserer, 2007). The presence of CD83-positive cells was reported in the B-dependent region of chicken peripheral lymphoid organs, which were follicular dendritic cells (FDCs) (Hansell et al., 2007). Subsequent to IBV infection, interferons and neutralising antibodies were found in the trachea, lung, kidney, liver, bile, and spleen (Otsuki et al., 1987, 1990).

While it is well-known that ellipsoid-associated cells (EACs) are the precursors of interdigitating dendritic cells (IDCs) and FDCs in the spleen (Oláh and Glick, 1982; Jeurissen et al., 1992; Igyártó et al., 2007), there is no information about the precursors of FDCs in the caecal tonsil (CT). The pathogenesis of IBV infection in the upper respiratory tract has been convincingly elucidated (Dhinakar Raj and Jones, 1997), but neither the viral effect on the lymphoid organs, nor 
the contribution of these organs to the production of MBL and other soluble components has been revealed yet. The aim of this work was to reveal the effects of coronavirus infection on the developing lymphoid organs using antibody against dendritic cells and MBL. The MBL expression in the EAC confirmed the early finding that EAC - as a resident cell of the spleen - is the precursor of splenic IDC and FDC (Oláh and Glick, 1982). The MBL and CD83 expressions may be provided a chance to identify dendritic cell precursors of the gutassociated lymphoid tissue (GALT).

\section{Materials and methods}

\section{Birds}

One-day-old specific-pathogen-free (SPF) White Leghorn chickens were obtained from Prophyl Ltd. (Mohács, Hungary) and placed in an isolator (Montair HM 1500, Koenenberg, The Netherlands). Feed and drinking water were provided ad libitum. All studies were conducted according to Directive 2010/63/ EU and the National Regulations about Animal Welfare and Ethics [Act 1988/ XXVIII modified by Act 2011/CLVIII and Conduct of Animal Trials (Government Regulation 40/2010)]. The National Food Chain Safety Office is authorised by the Pest County Government Office to perform animal tests for experimental purposes. Seven test groups for field QX isolates and the vaccine strain were formed (each including 10 birds) as well as a non-infected, negative control group (with 10 birds). For immunocytochemistry and histological examinations, two birds were sacrificed at $5,7,10$, and occasionally 15 or 17 days post infection (dpi).

\section{Virus isolates}

Six IBV QX field isolates $(11518,13887,20162,21776,13547,11638)$ (Kiss et al., 2015) and the H-120 vaccine strain were used in these studies. IBV field isolates and the vaccine strain were provided by the Veterinary Diagnostic Directorate of the National Food Chain Safety Office Virus titres were determined by egg titration. Briefly, serial dilutions of each examined infectious material were prepared. A $0.1-\mathrm{ml}$ volume of each dilution was inoculated in the allantois cavity of 9-day-old embryonated eggs. Eight embryonated eggs per dilution were used. The titres were as follows: $10^{6.77} \mathrm{EID}_{50} / 0.1 \mathrm{ml}(11518), 10^{6.7} \operatorname{EID}_{50} / 0.1 \mathrm{ml}$ (13887), $10^{5.7} \mathrm{EID}_{50} / 0.1 \mathrm{ml}(20162), 10^{6.88} \mathrm{EID}_{50} / 0.1 \mathrm{ml}(21776), 10^{5.9} \mathrm{EID}_{50} / 0.1 \mathrm{ml}$ (13547), and $10^{2.7} \mathrm{EID}_{50} / 0.1 \mathrm{ml}(11638)$, while the titre of the $\mathrm{H} 120$ vaccine strain was $10^{6.36} \mathrm{EID}_{50} / 0.1 \mathrm{ml}(\mathrm{H} 120)$. 


\section{Infection}

Ten one-day-old birds were oronasally infected with $0.05 \mathrm{ml}$ of the QX isolates and the $\mathrm{H}-120$ vaccine strain. The same volume of phosphate-buffered saline (PBS) was given oronasally to the negative control birds $(n=10)$.

\section{Antibodies}

The following monoclonal antibodies $(\mathrm{mAb})$ were used for $\mathrm{T}$ cells: antiCD4 and CD8 (Thermofisher Scientific); for B cells Bu1 (Ígyártó et al., 2008); for monocytes/macrophages: 68.2 (Thermofisher Scientific) and KUL01 (BioRad); for dendritic cells: 74.3 and CD83; and anti-MBL: MBL clone 6B11 (1:20) (Bioporto). Antigens were purified from chicken plasma, while CD83 was provided by Collin Butter at 1:200 dilutions for antibody staining (Staines et al., 2013). The paper induces only the results obtained with anti-MBL and CD83, because the other antibodies did not show valuable differences between control and infected birds.

\section{Immunohistochemistry}

Tissue samples (spleen and CT) were embedded in liver and frozen in liquid nitrogen. The embedding process began with labelling an approximately $1.5 \times 1.5 \mathrm{~cm}^{2}$ piece of cardboard with the necessary information. The other side of the cardboard was covered with a flat piece of liver cut from the same experimental bird. The tissue samples to be tested were placed on the liver and covered by the rest of the liver to protect the sample from sudden cold.

Before starting the experiment, a thermoflask (about one litre in volume) was filled with liquid nitrogen, and a piece of polystyrene foam $(1 \mathrm{~cm}$ thick and $8-10 \mathrm{~cm}$ in diameter) was placed on the surface of the liquid nitrogen. The floating polystyrene foam cooled down in a few minutes. The liver-embedded tissue samples attached to the cardboard were placed onto the floating polystyrene foam. When the blocks became frozen (the colour of the liver had changed) and tilted the polystyrene, the block slid into the liquid nitrogen. The blocks were put in a capped tube and stored at $-80{ }^{\circ} \mathrm{C}$ until cryostat sectioning.

The $10-\mu \mathrm{m}$ cryostat sections were fixed in cold acetone for $15 \mathrm{~min}$ and rehydrated in PBS. The sections were incubated with primary antibodies at room temperature for $45 \mathrm{~min}$. After PBS washing, isotype-specific biotinylated secondary antibodies were used. The endogenous peroxidase reaction was either blocked by $3 \% \mathrm{H}_{2} \mathrm{O}_{2}$ for $10 \mathrm{~min}$ or developed by 3,3'-diaminobenzidine. An $\mathrm{ABC}$ kit was used to enhance the signals of primary antibodies. The binding sites of primary antibodies were detected by 4-chloro-naphtol. For control staining, PBS replaced either the primary or the secondary antibodies, and occasionally an irrelevant isotype-specific antibody was also employed. 


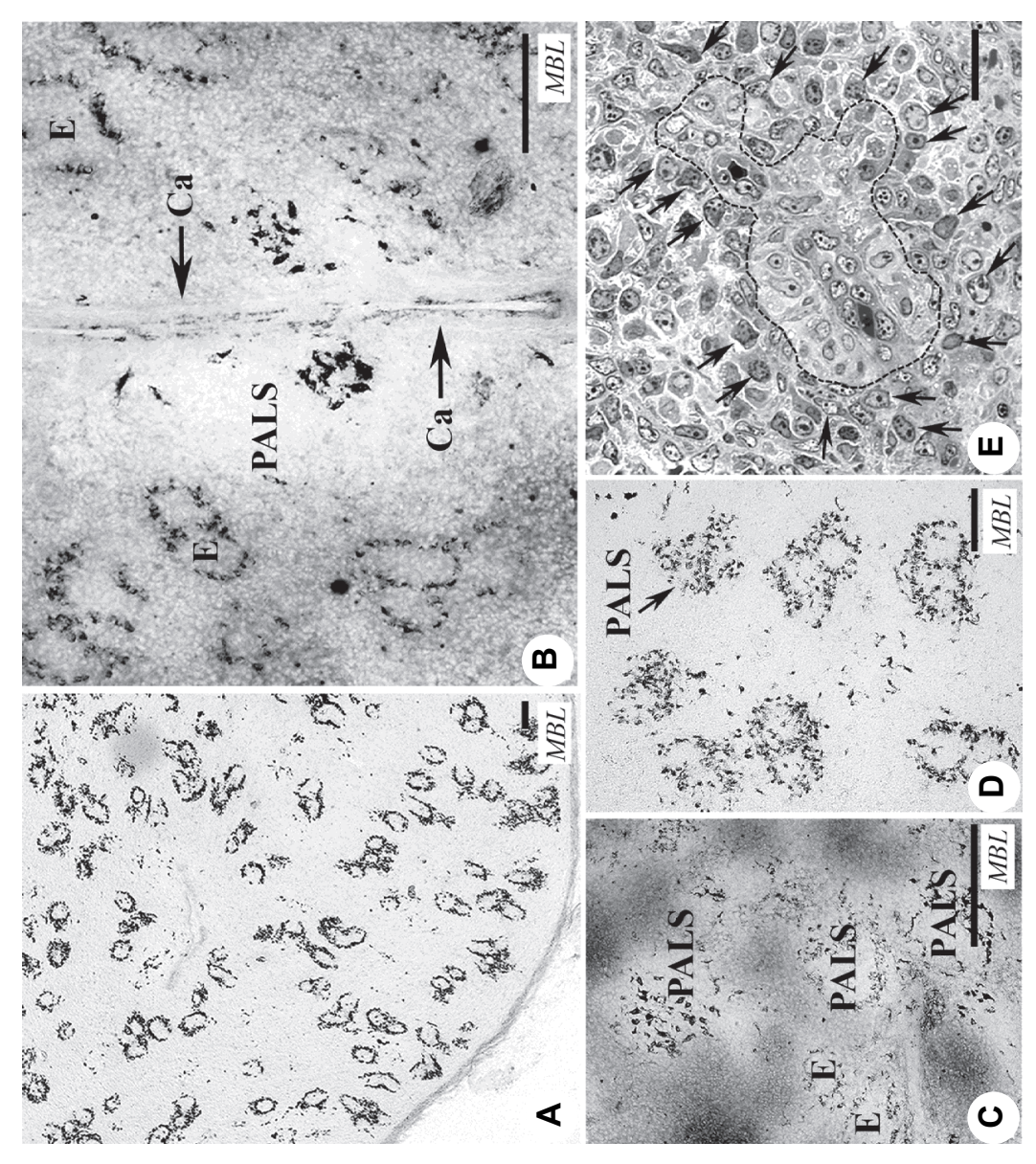

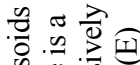

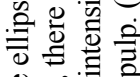

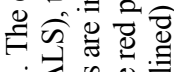

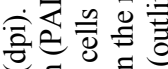

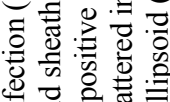

琼

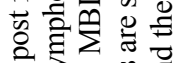

帘

$\circ$ 뜽요

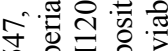

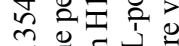

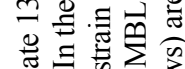

을

중 $-\frac{0}{4}$ 엉

उ.

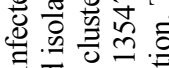

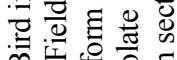

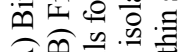

宅包券

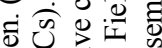

क्य造它

on

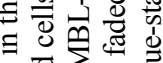

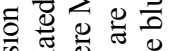

क.

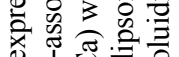

$0 . \overline{0}=$

党常

$\sum_{0}=$

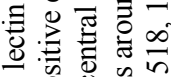

on

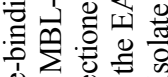

要

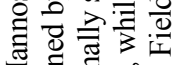

语恶

这施娄 
In the spleen, the staining patterns of anti-MBL and CD83 were highly similar. Therefore, double staining was done to determine their possible colocalisation. The procedure of double staining followed the staining procedure described above step by step. The binding sites of primary antibodies, MBL and CD83 were visualised by 3-amino-9-ethylcarbazol (Vector Laboratories, Burlingame, USA, brown) and 4-chloro-naphtol (Sigma-Aldrich, St. Louis, USA, blue), respectively.

\section{Histology}

The tissue samples were fixed with $4 \%$ phosphate-buffered glutaraldehyde at $4{ }^{\circ} \mathrm{C}$ overnight. PBS was used to remove the excess fixative, and the samples were post-fixed in $1 \%$ osmium tetroxide for $2 \mathrm{~h}$. The samples were dehydrated in graded ethanol and embedded in a mixture of araldite and epoxy resin (Polysciences, Warrington, PA, USA). One-micron-thick sections (semi-thin sections) were stained with $1 \%$ toluidine blue.

\section{Image processing}

Images were processed using Adobe Photoshop version No. 7.0 (Adobe Systems, California, USA).

\section{Results and discussion}

MBL was not detectable in the spleen of the negative control birds during the observation period. In the groups infected with QX isolates and the H120 vaccine strain the spleens were MBL negative at $5 \mathrm{dpi}$, while by 7 dpi all groups produced MBL in the EACs and cell clusters in the PALS around the central artery (Figs 1A, B and C). The EACs are elongated splenic resident cells of haemopoietic origin (Figs 1B, C and D). The finding that MBL staining appeared late post infection (by $7 \mathrm{dpi}$ ) underlines the possibility that it may be induced by inflammatory cytokine(s) and not directly by the virus.

Otsuki et al. $(1987,1990)$ described the presence of coronavirus in the spleen without histological and functional damages, while Nielsen et al. (1998) reported the presence of MBL-positive, degenerate, macrophage-like cells around the ellipsoid induced by IBDV infection. In our study all cells proved to be viable, which seems to confirm the observations of Otsuki et al. $(1987,1990)$. The semi-thin sections show neither degenerating nor apoptotic cells around the ellipsoid, and in the peri-ellipsoidal white pulp (PWP), which is a B-dependent region (Fig. 1E).

In the spleen the staining pattern of CD83 was highly similar to that of MBL (Fig. 2A), which initiated the double staining of MBL and CD83. Dendritic cell precursors express CD83 antigen which is present in membrane-bound and 
soluble forms (Hock et al., 2001). Double staining proved that the majority of MBL-positive EACs also expressed CD83 (Fig. 2B). However, in the PALS among the cluster cells, there were occasionally single MBL-positive and/or CD83-positive ones (Figs 2C and D).

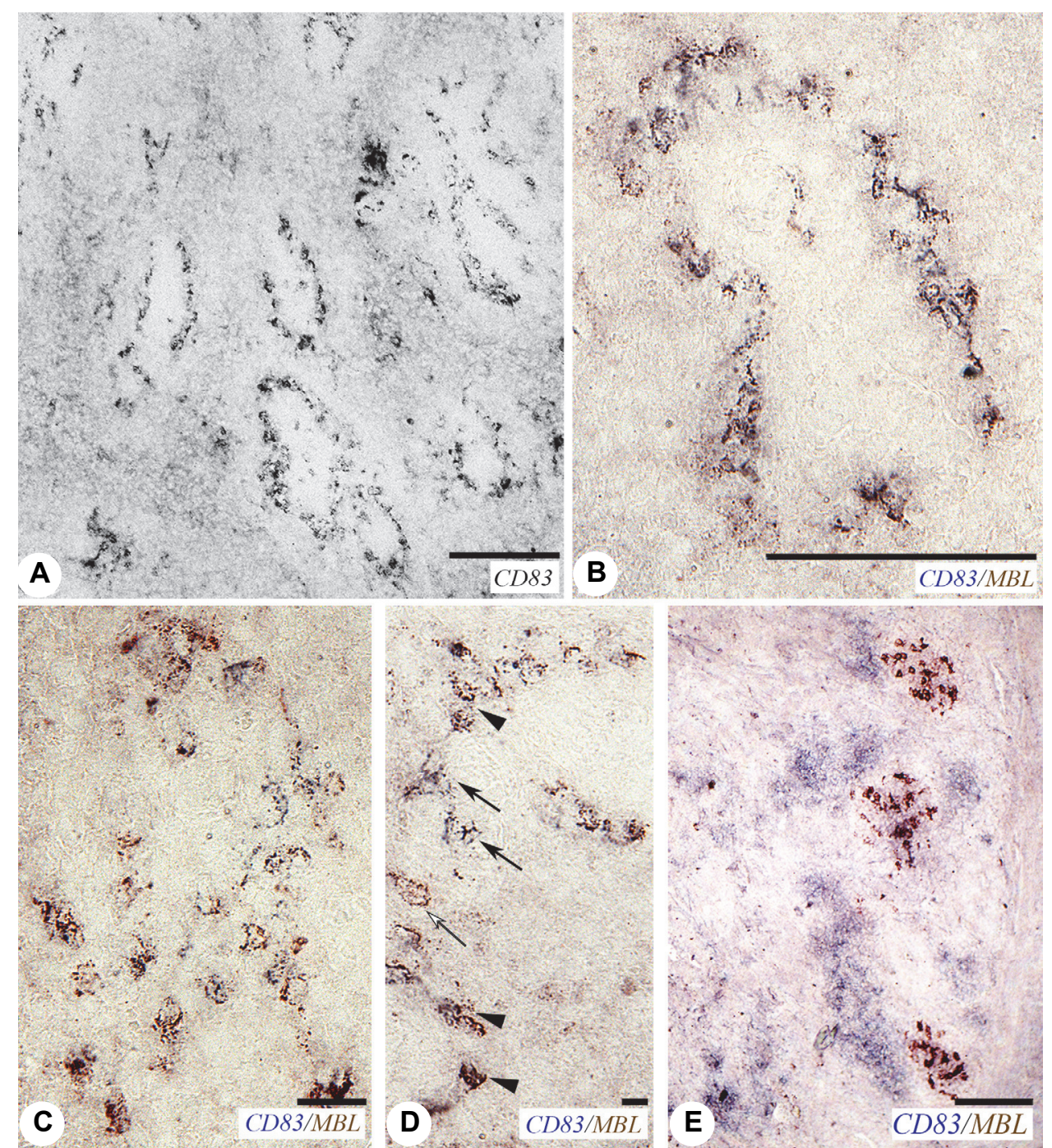

Fig. 2. MBL-positive cells express CD83 in the spleen. (A-D) Field isolate 13887, 10 dpi. (A) CD83 antibody shows a similar staining pattern to MBL (see Fig. 1D). (B) Double staining of MBL and CD83. MBL-positive EACs express CD83. (C) In the PALS, the clustered MBL-positive cells express CD83. (D) Single positive MBL (brown, open arrow) and CD83 (blue, arrow) can be found among the double positive cells (arrowhead). (E) Caecal tonsil (CT), 8-day-old control bird. MBL-positive cells form germinal centre-like groups (brown), and CD83-positive cells show patchy staining (blue) indicating co-localisation of MBL and CD83 


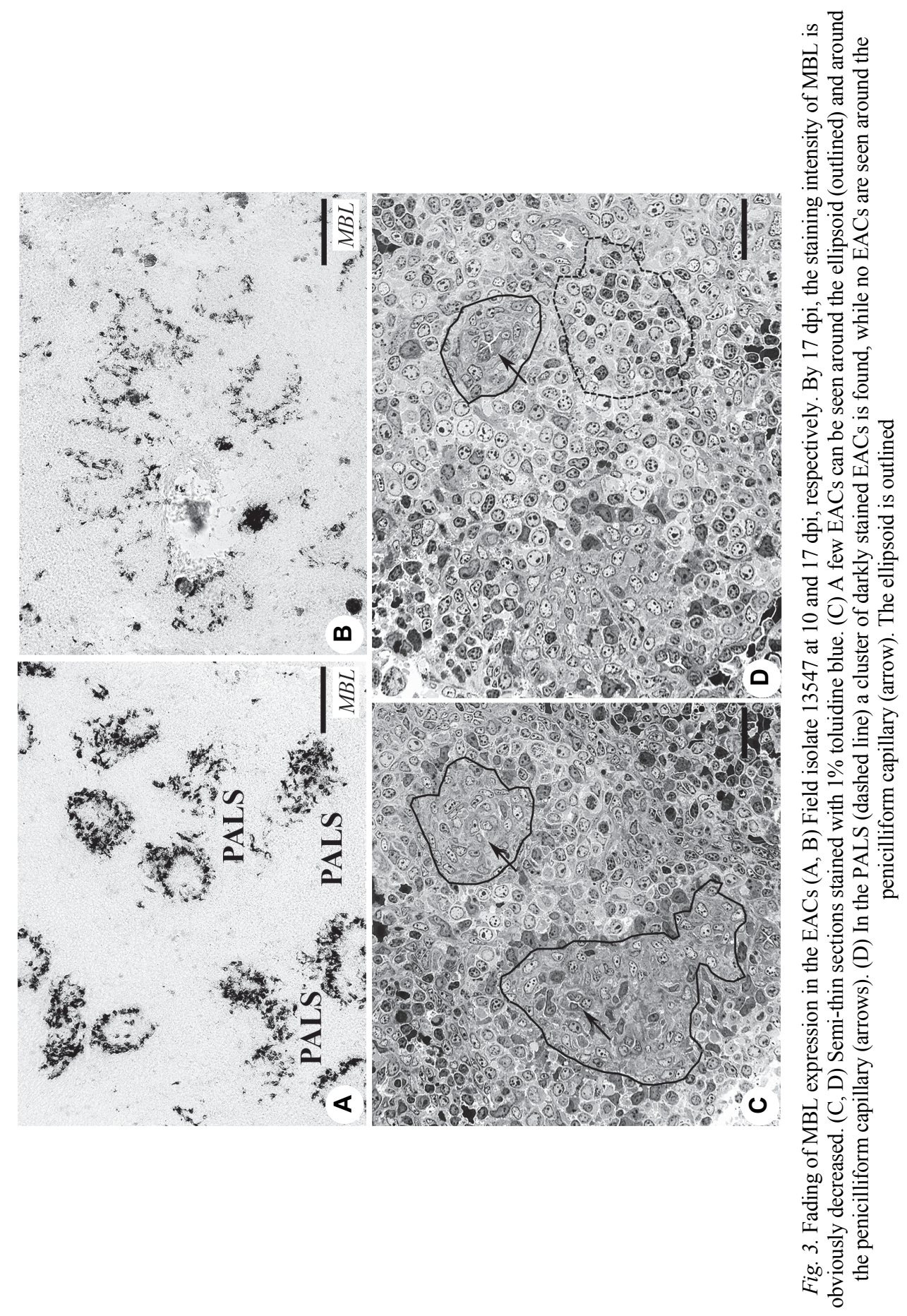




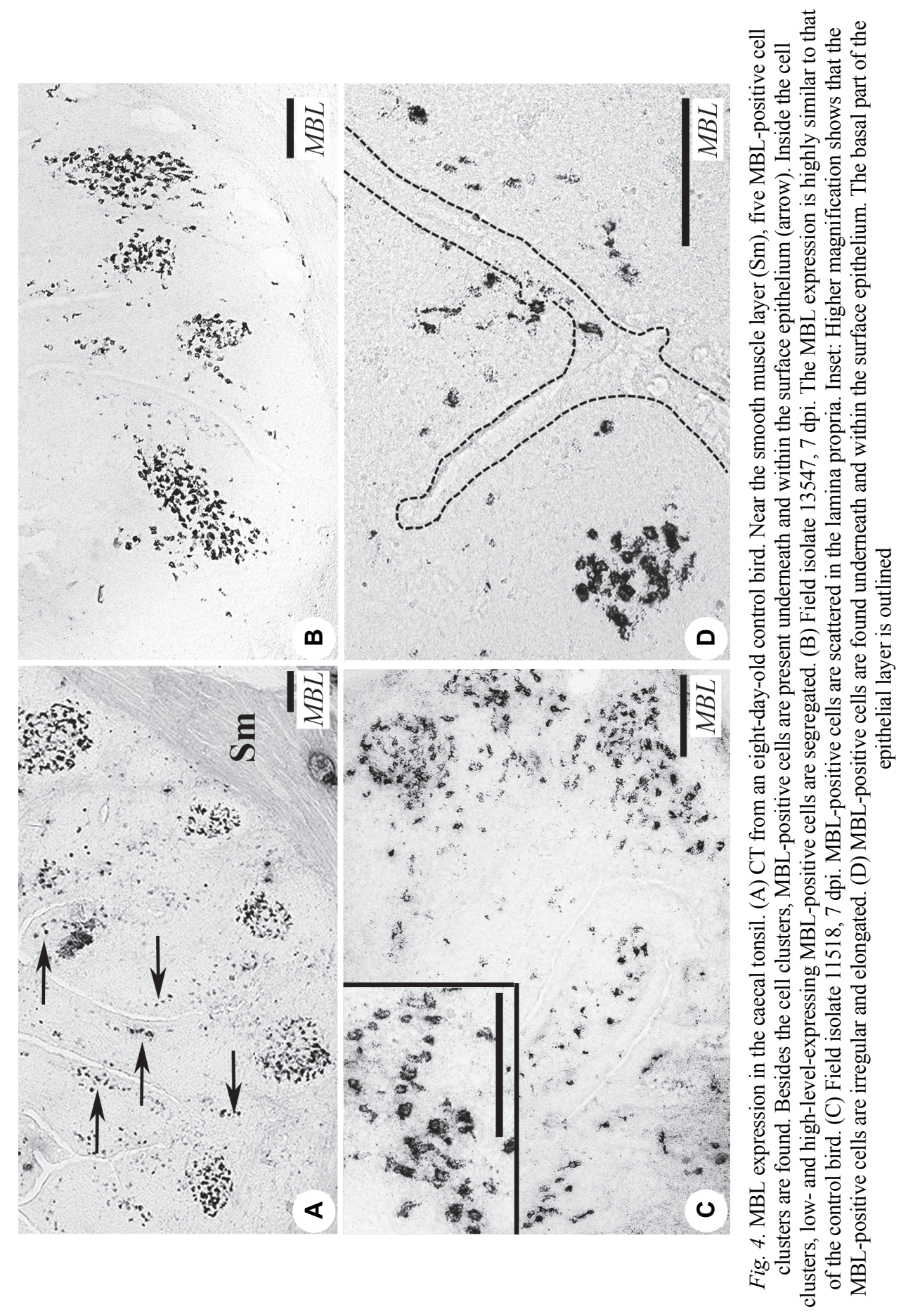


The MBL staining was most intense around $10 \mathrm{dpi}$, while a decrease of MBL staining was clearly recognisable by 17 dpi (Figs 3A and B). The semi-thin sections indicated that around the ellipsoids the number of EACs was highly variable at 15 dpi (Figs $3 \mathrm{C}$ and D). This finding shows that after IBV infection the antigen capture system (ellipsoid, EAC) and the B-dependent region (PWP) regenerate very slowly. The development of bursal follicles is also retarded (Farsang et al., 2018), which influences the splenic B-dependent areas.

The MBL-positive cell clusters in the developing PALS are the rudiments of the GC. In eight-day-old control birds, there is no histological sign of GC based on haematoxylin-eosin staining and electron microscopy. Thus, the MBL expression in the cell clusters indicates that the functional changes precede the morphological manifestation of the GC. To a viral or inflammatory stimulus, the EACs not only produce MBL but also express CD83, which shows that the virus infection facilitates the maturation of dendritic cell precursors. Therefore, monitoring the MBL expression is one of the useful methods for monitoring the formation of GC. The MBL and CD83 are co-localised in the EACs and GC-like cell clusters, but co-localisation of MBL and CD83 cannot be detected in the CT (Fig. 2 E).

Contrary to the findings in the spleen, the CD83 shows separate "patchlike' staining in the caecal tonsils (CT), which is similar to the staining pattern of CD83 in thymic dendritic cells of chickens (Bódi et al., 2015). In the CT MBL is expressed in both the control (Fig. 4B) and the IBV-infected birds. The MBLpositive cells can be found at two locations: in GC-like clusters and under the surface and occasionally within the epithelium (Figs 4A, C and D). Surprisingly, the cells are segregated according to the intensity of the MBL expression in the GC-like clusters (Fig. 4A). The reason for this segregation has not been elucidated yet. However, the low MBL-expressing cells generally accumulate on the side of the cell cluster that faces towards the surface epithelium. This may show that these MBL-positive cells arrived later into the cell cluster. The high MBLexpressing cells may be matured, dendritic cells.

Some studies suggested that MBL production in the CT had been 'unique', because it appeared without virus infection (Nielsen et al., 1998). However, an alternative explanation for the appearance of early MBL production could be that certain 'natural' antigens in the feed can stimulate dendritic cell precursors for MBL production.

There is no information about the dendritic cell precursors in the CT, but the MBL expression may provide a chance for their identification. In the CT the MBL-producing cells do not show co-localisation with $\mathrm{CD} 83^{+}$cells, therefore the MBL-producing and the $\mathrm{CD} 83^{+}$cells can represent two different stromal cell populations. In the spleen the EACs are the precursors of FDC and IDC, and they are positive for MBL production and CD83 antigen. It can be assumed that in the $\mathrm{CT}$ the scattered MBL-positive cells may represent FDC precursors and the cells 
in the CD83-positive patchy areas belong to the IDC population. Thus, in the spleen the FDC and IDC have a common precursor, EAC, which produces MBL and expresses CD83, while in the CT the FDC and IDC have separate precursors: the FDC precursors produce MBL and are CD83 negative, while the cells in the $\mathrm{CD} 83^{+}$patchy areas represent immature and/or mature IDC.

The spleen is connected to the circulation, while the CT is a part of the gut-associated lymphoid tissue (GALT). The differences in the dendritic cell precursors between spleen and CT may be related to their anatomical location. In the $\mathrm{CT}$ two independent cell systems (MBL-producing and CD83 ${ }^{+}$) may provide a certain level of autonomy for the mucosal immune system. The EACs migrate along the penicilliform capillary, not through the red pulp (White et al., 1970), therefore the EACs do not enter the circulation, which means that EACs are exclusively precursors for splenic FDCs and IDCs (Jeurissen and Janse, 1996; Igyártó et al., 2007). The KUL01 mAb recognises chicken monocyte/macrophage cells of haemopoietic origin (Mast et al., 1998). Staines et al. (2014) reported that the KUL01 mAb precipitated a molecule, which is a homologue of the mammalian mannose receptor called MRC1L-B. The mammalian mannose receptor (MRC-1) is a pattern recognition receptor, which is involved in antigen uptake and presentation. This molecule is not restricted to macrophages, it is also present on the dendritic cell precursors (Sallusto et al., 1995), which has an antigen capture role. In the CT the two separate dendritic cell precursors provide further evidence for the common origin and tight functional role of macrophage/ dendritic cells.

\section{Acknowledgements}

This work was carried out in the framework of the COST Action on Controlling Avian Coronaviruses (FA1207). Dr. Farsang and Dr. Bódi contributed equally in experimental work and compilation of the manuscript. Dr. Farsang's contribution was kindly supported by the 'Bolyai János Research Fellowship' of the Hungarian Academy of Sciences (BO/125/13). The CD83 mAb was a generous gift from Collin Butter (Pirbright Institute, Campton, UK). This research did not receive any specific grant from funding agencies in the public, commercial, or non-profit sectors.

\section{References}

Ambali, A. G. and Jones, R. C. (1990): Early pathogenesis in chicks of infection with an enterotropic strain of infectious bronchitis virus. Avian Dis. 34, 809-817.

Bódi, I., Minkó, K., Molnár, D., Nagy, N. and Oláh, I. (2015): A novel aspect of the structure of the avian thymic medulla. Cell and Tissue Res. 359, 489-501.

Cavanagh, D. (2007): Coronavirus avian infectious bronchitis virus. Vet. Res. 38, 281-297.

Cook, J. K. A. (1971): Recovery of infectious bronchitis virus from eggs and chicks produced by experimentally inoculated hens. J. Comp. Pathol. 81, 203-211. 
Cumming, R. B. (1962): The etiology of uraemia of chickens. Aust. Vet. J. 38, 554.

Dalgaard, T., Skovgaard, K., Norup, L. R., Pleidrup, J., Permin, A., Schou, T. W., Vadekar, D. F., Jungersen, G. and Juul-Madsen, H. R. (2015): Immune gene expression in the spleen of chickens experimentally infected with Ascaridia galli. Vet. Immunol. Immunopathol. 164, 79-86.

Dhinakar Raj, G. and Jones, R. C. (1997): Infectious bronchitis virus: Immunopathogenesis of infection in the chicken. Avian Pathol. 26, 677-706.

Farsang, A., Bódi, I., Fölker, O., Minkó, K., Benyeda, Zs., Bálint, Á., Kiss, L. A. and Oláh, I. (2018): Coronavirus infection retards the development of the cortico-medullary capillary network in the bursa of Fabricius of chicken. Acta Vet. Hung. 66, 20-27.

Flores-Romo, L. (2001): In vivo maturation and migration of dendritic cells. Immunology 102, $255-262$.

Gelb, J. Jr., Lunt, R. L., Metz, A. L. and Fries, P. A. (1991): Attenuation of avian infectious bronchitis virus by cold adaptation. Avian Dis. 35, 847-853.

Gunn, M. D. (2003): Chemokine mediated control of dendritic cell migration and function. Semin. Immunol. 15, 271-276.

Hamzić, E., Kjarup, R. B., Mach, N., Minozzi, G., Strozzi, F., Gualdi, V., Williams, J. L., Chen, J., Wattrang, E., Buitenhuis, B., Juul-Madsen, H. R. and Dalgaard, T. S. (2016): RNA sequencing-based analysis of the spleen transcriptome following infectious bronchitis virus infection of chickens selected for different mannose-binding lectin serum concentrations. BMC Genomics 17, 82.

Hansell, C., Zhu, X. W., Brooks, H., Sheppard, M., Withanage, S., Maskell, D. and McConnell, I. (2007): Unique features and distribution of the chicken CD83+ cell. J. Immunol. 179, $5117-5125$.

Hock, B. D., Kato, M., McKenzie, J. L. and Hart, D. N. (2001): A soluble form of CD83 is released from activated dendritic cells and B lymphocytes, and is detectable in normal human sera. Int. Immunol. 13, 959-967.

Igyártó, B. Z., Magyar, A. and Oláh, I. (2007): Origin of follicular dendritic cell in the chicken spleen. Cell and Tissue Res. 327, 83-92.

Igyártó, B. Z., Nagy, N., Magyar, A. and Oláh, I. (2008): Identification of the avian B-cell-specific Bu1 alloantigen by a novel monoclonal antibody. Poult. Sci. 87, 351-355.

Jeurissen, S. and Janse, E. M. (1996): The microenvironment of the chicken immune system. In: Davison, T. F., Morris, T. R. and Payne, L. N. (eds) Poultry Immunology. Poultry Science Symposium Series, Vol. 24. Carfax Publishing Company, Abingdon. pp. 47-66.

Jeurissen, S., Claassen, E. and Janse, E. M. (1992): Histological and functional differentiation of non-lymphoid cells in the chicken spleen. Immunology 77, 75-80.

Kinde, H., Daft, B. M., Castro, A. E., Bickford, A. A., Gelb, J. and Reynolds, B. (1991): Viral pathogenesis of a nephrotropic infectious bronchitis virus isolated from commercial pullets. Avian Dis. 35, 415-421.

Kiss, I., Mató, T., Homonnay, Z. G., Kojer, J., Farsang, A., Bálint, Á. and Palya, V. (2015): Survey indicates circulation of 4/91 and QX-type infectious bronchitis viruses in Hungary in 2014 - Short communication. Acta Vet. Hung. 63, 382-388.

Kjaerup, R. M., Dalgaard, T. S., Norup, L. R., Bergman, I. M., Sorensen, P. and Juul-Madsen, H. R. (2013): Adjuvant effects of mannose-binding lectin ligands on the immune response to infectious bronchitis vaccine in chickens with high or low serum mannose-binding lectin concentrations. Immunobiology 219, 263-274.

Kjaerup, R. M., Dalgaard, T. S., Norup, L. R., Hamzic, E., Sorensen, P. and Juul-Madsen, H. R. (2014): Characterization of cellular and humoral immune responses after IBV infection in chicken lines differing in MBL serum concentration. Viral Immunol. 27, 529-542.

Lambrechts, C., Pensaert, M. and Ducatelle, R. (1993): Challenge experiments to evaluate crossprotection induced at the trachea and kidney level by vaccine strains and Belgian nephropathogenic isolates of avian infectious bronchitis virus. Avian Pathol. 22, 577-590. 
Laursen, S. B., Dalgaard, T. S., Thiel, S., Lim, B. L., Jensen, T. V., Juul-Madsen, H. R., Takahashi, A., Hamana, T., Kawakami, M. and Jensenius, J. C. (1998): Cloning and sequencing of a cDNA encoding chicken mannan-binding lectin (MBL) and comparison with mammalian analogues. Immunology 93, 421-430.

Lechmann, M., Berchtold, S., Hauber, J. and Steinkasserer, A. (2002): CD83 on dendritic cells: more than just a marker for maturation. Trends Immunol. 23, 273-575.

Mast, J., Goddeeris, B. M., Peeters, K., Vandesande, F. and Berghman, L. R. (1998): Characterisation of chicken monocytes, macrophages and interdigitating cells by the monoclonal antibody KUL01.Vet. Immunol. Immunopathol. 61, 343-357.

Nielsen, O. L., Jorgensen, P. H., Hedemand, J., Jensenius, J. C., Koch, C. and Laurse, S. B. (1998): Immunohistochemical investigation of the tissue distribution of mannan-binding lectin in noninfected and virus-infected chickens. Immunology 94, 122-128.

Nielsen, O. L., Jensenius, J. C., Jorgensen, P. H. and Laursen, S. B. (1999): Serum levels of chicken mannan-binding lectin (MBL) during virus infections; indication that chicken MBL is an acute phase reactant. Vet. Immunol. Immunopathol. 70, 309-316.

Oláh, I. and Glick, B. (1982): Splenic white pulp and associated vascular channels in chicken spleen. Am. J. Anat. 165, 445-480.

Otsuki, K., Huggins, M. B. and Cook, J. K. A. (1990): Comparison of the susceptibility to avian infectious bronchitis virus infection of two inbred lines of White Leghorn chickens. Avian Pathol. 19, 467-475.

Otsuki, K., Nakamura, T., Kubota, N., Kawaoka, Y. and Tsubokura, M. (1987): Comparison of two strains of avian infectious bronchitis virus for their interferon induction, viral growth and development of virus-neutralizing antibody in experimentally-infected chickens. Vet. Microbiol. 12, 31-40.

Picault, J. P., Drouin, P., Toux, J. Y., Guittet, M. and Bennejean, G. (1991): Infectious bronchitis in France: epidemiological situation and prophylactic practices. Proceedings of the IInd International Symposium on Infectious Bronchitis, Rauischholzhausen, Germany. pp. 3-22.

Prazma, C. M. and Tedder, T. F. (2007): Dendritic cell CD83: a therapeutic target or innocent bystander? Immunol. Lett. 115, 1-8.

Prechtel, A. T. and Steinkasserer, A. (2007): CD83: an update on functions and prospects of the maturation marker of dendritic cells. Arch. Dermatol. Res. 299, 59-69.

Randolph, G. J., Angeli, V. and Swartz, M. A. (2005): Dendritic-cell trafficking to lymph nodes through lymphatic vessels. Nat. Rev. Immunol. 5, 617-628.

Sallusto, F., Cella, M., Danieli, C. and Lanzavecchia, A. (1995): Dendritic cells use micropinocytosis and the mannose receptor to concentrate macromolecules in the major histocompatibility complex class II compartment: downregulation by cytokines and bacterial products. J. Exp. Med. 182, 389-400.

Schou, T. W., Permin, A., Christensen, J. P., Cu, H. P. and Juul-Madsen, H. R. (2010): Mannanbinding lectin (MBL) in two chicken breeds and the correlation with experimental Pasteurella multocida infection. Comp. Immunol. Microbiol. Infect. Dis. 33, 183-195.

Staines, K., Hunt, L. G., Young, J. R. and Butter, C. (2014): Evolution of an expanded mannose receptor gene family. PLoS One 12, e110330.

Staines, K., Young, J. R. and Butter, C. (2013): Expression of chicken DEC205 reflects the unique structure and function of the avian immune system. PLoS One 8, e51799.

Toro, H., Godoy, V., Larenas, J., Reyes, E. and Kaleta, E. F. (1996): Avian infectious bronchitis viral persistence in the Harderian gland and histological changes after eye-drop vaccination. Avian Dis. 40, 114-120.

Ulrich-Lynge, S. L., Dalgaard, T. S., Norup, L. R., Kjaerup, R. M., Olsen, J. E., Sorensen, P. and Juul-Madsen, H. R. (2015a): The consequence of low mannose-binding lectin plasma concentration in relation to susceptibility to Salmonella Infantis in chickens. Vet. Immunol. Immunopathol. 163, 23-32. 
Ulrich-Lynge, S. L., Dalgaard, T. S., Norup, L. R., Song, X., Sorensen, P. and Juul-Madsen, H. R. (2015b): Chicken mannose-binding lectin function in relation to antibacterial activity towards Salmonella enterica. Immunobiology 220, 555-563.

White, R. G., French, V. I. and Stark, J. M. (1970): A study of the localisation of a protein antigen in the chicken spleen and its relation to the formation of germinal centres. J. Med. Microbiol. 3, 65-83.

Zhang, W., Bouwman, K. M., van Beurden, S. J., Ordonez, S. R., van Eijk, M., Haagsman, H. P., Verheije, M. H. and Veldhuizen, E. J. A. (2017): Chicken mannose binding lectin has antiviral activity towards infectious bronchitis virus. Virology 509, 252-259.

Zhou, L. J. and Tedder, T. F. (1995): Human blood dendritic cells selectively express CD83, a member of the immunoglobulin superfamily. J. Immunol. 154, 3821-3835.

Zhou, L. J., Schwarting, R., Smith, H. M. and Tedder, T. F. (1992): A novel cell-surface molecule expressed by human interdigitating reticulum cells, Langerhans cells, and activated lymphocytes is a new member of the Ig superfamily. J. Immunol. 149, 735-742. 